\title{
Chromosomal assignment of seven genes on canine chromosomes by fluorescence in situ hybridization
}

\author{
M.L. Guevara-Fujita, ${ }^{1}$ R. Loechel, ${ }^{1}$ P.J. Venta, ${ }^{2}$ V. Yuzbasiyan-Gurkan, ${ }^{2}$ G. J. Brewer ${ }^{1}$ \\ ${ }^{1}$ Department of Human Genetics, University of Michigan Medical School, 4708 Medical Science Building II, \\ Ann Arbor, Michigan 48109-0618, U.S.A. \\ ${ }^{2}$ College of Veterinary Medicine, Michigan State University, East Lansing, Michigan
}

Received: 18 August 1995 / Accepted: 17 November 1995

\begin{abstract}
Our group has developed more than 600 DNA markers to build a map of the canine genome. Of these markers, 125 correspond to genes (anchor loci). Here we report the first six autosomal genes assigned to canine chromosomes by fluorescence in situ hybridization (FISH), using cosmid DNA: adenine phosphoribosyl transferase on Chromosome (Chr) 3; creatine kinase muscle type on Chr 4; pyruvate kinase liver and red blood cell type on Chr 2; and colony-stimulating factor-1 receptor, glucose transporter protein-2, and tumor protein $\mathrm{p} 53$ on Chr 5 . These assignments are based on the karytotype proposed by Stone and associates (Genome 34, 407, 1991) using high-resolution techniques. In addition, we have assigned the Menkes gene to the $\mathrm{X} \mathrm{Chr}$ of the dog.
\end{abstract}

\section{Introduction}

We have been conducting a major project for the last five years developing about 600 canine DNA markers. This project, which has received financial support from the American Kennel Club, the Morris Animal Foundation, and the Orthopedic Foundation for Animals, has as its major objective the development of a linked marker approach to canine genetic diseases. The canine DNA markers are of two types; approximately 500 of them are microsatellites, and about 125 are anchor loci. Anchor loci are actual genes previously cloned in other species, for which we have isolated a portion of the canine homolog. Since genes are conserved and microsatellites generally are not, the inclusion of anchor loci markers allows us to begin developing a canine genetic map that can be related to the genetic map of other species. The development of a genetic map for species offers many advantages. For the dog, a major area will be the use of homologous maps in the human and mouse to develop candidate genes for a canine genetic disease.

We have developed 125 canine anchor loci that we plan to map to specific dog chromosomes, using fluorescence in situ hybridization (FISH) and G-banded karyotypes. Herein we demonstrate the localization of seven genes, six of which are autosomal, the first autosomal genes mapped by in situ hybridization in the dog.

\section{Materials and methods}

Anchor loci isolation and probe generation. Polymerase chain reaction (PCR) primers for each of the anchor loci reported were designed based on conserved regions in homologous genes of other mammalian genomes (Venta et al., manuscript submitted). The PCR product obtained from the canine genome was sequenced and its homology to the human and

Correspondence to: M.L. Guevara-Fujita mouse investigated to verify the identity of the canine product. These primers were used to screen a canine genomic cosmid library. Sub-libraries that yielded PCR products of an expected size were rescreened by colony hybridization with PCR products oligo-labeled with $\alpha-{ }^{32} \mathrm{P}-\mathrm{dCTP}$ as probes. Positive colonies were picked and used as templates in PCR reactions with the appropriate primers to verify the identify of the clone. In some cases, sequencing reactions were carried out to further confirm their identity.

Cosmid DNAs were prepared with a standard alkaline lysis protocol (Sambrook et al. 1989). One microgram of each cosmid was labeled with biotin 14-dATP according to the Bio-Nick Labeling System (Gibco-BLR), to generate $200-500$ base pair long fragments.

Chromosome preparation, in situ hybridization, and posthybridization banding. To obtain chromosome spreads, lymphocyte cultures were synchronized with methotrexate and treated with 5-bromodeoxyuridine for the final $5 \mathrm{~h}$ before harvest, as described by Stone et al. (1991). The FISH technique was performed according to Yu and colleagues (1992) with some modifications. Briefly, for each slide, 100-150 ng of biotinylated probe was used in the presence of $75 \times-100 \times$ excess sheared dog genomic DNA and herring testes DNA to suppress background. Signals were detected with fluorescein avidin D (Vector) and one amplification step. Chromosomes were examined with a Leitz Orthoplan fluorescent microscope and photographed with Ektachrome 400 ASA Kodak film. After the signals were recorded, the slides were washed in $4 \times S S C / 0.5 \%$ Tween 20 and stained with Wright stain solution in phosphate buffer pH 6.7 to obtain G-bands.

For each cosmid probe, 10-20 metaphases were analyzed. Chromosomes with signals were identified by G-banding and shown to be the same. At least three complete karyotypes were constructed for each probe.

\section{Results}

The karyotyping carried out in this study was based on the idiogram proposed by Stone and coworkers (1991). In situ hybridization of cosmid probes gave good signals on distinct chromosomes. The first probe hybridized, as a partial check on the procedure, was the Menkes gene $(M N K)$, which hybridized to $\mathrm{Xq}$ as expected (Table 1).

A series of six autosomal genes were studied. Their assignments in the dog are presented in Table 1 along with their human and mouse chromosomal assignments and any human diseases caused by defects in these genes.

For the MNK cosmid we recorded 11 metaphases (six from a female culture, 5 from a male culture), obtaining signals on $41 \%$ of chromatids. We analyzed 27 metaphases from the APRT cosmid, obtaining signals in $63 \%$ of the chromatids; for CKMM, 20 metaphases were analyzed and signals recorded in $68 \%$ of chromatids. CSF1R gave signals on $82 \%$ of chromatids ( 28 metaphases recorded). GLUT2 had 24 metaphases analyzed and signals in 95\% of the chromatids; for PKLR, 22 metaphases were analyzed and signals were found on 92\% of the chromatids, and TP53 had 37 metaphases analyzed and signals on $62 \%$ of chromatids. For the 
Table 1. Chromosome assignment of anchor loci (genes) in the dog.

\begin{tabular}{|c|c|c|c|c|}
\hline \multirow[b]{2}{*}{ Cosmid anchor loci probes } & \multicolumn{3}{|c|}{ Chromosomal Assignments } & \multirow[b]{2}{*}{ Associated diseases } \\
\hline & Dog & Human & Mouse $^{\mathrm{a}}$ & \\
\hline MNK (ATPase, $\mathrm{CU}^{++}$transporting, alpha polypeptide) & $\mathrm{X}$ & $\begin{array}{l}\text { Xq13.2-q13.3 } \\
\text { Verga et al. (1991) }\end{array}$ & $\mathrm{X}(\mathrm{Mo})$ & Menkes disease \\
\hline APRT (Adenine phosphoribosyl transferase) & 3 & $\begin{array}{l}16 \text { q } 24 \\
\text { Fratini et al. (1986) }\end{array}$ & 8 (Aprt) & urolithiasis \\
\hline CKMM (Creatine kinase muscle type) & 4 & $\begin{array}{l}\text { 19q13.3 } \\
\text { Nigro et al. (1987) }\end{array}$ & $7(\mathrm{Ckmm})$ & \\
\hline CSFIR (Colony stimulating factor 1-receptor) & 5 & $\begin{array}{l}5 q 33 \\
\text { LeBeau et al. (1986) }\end{array}$ & 18 (Csfmr) & c-fms proto-oncogene \\
\hline GLUT2 (Glucose transporter protein-2) & 5 & $\begin{array}{l}3 \mathrm{q} 26 \\
\text { Fukumoto et al. (1988) }\end{array}$ & 3 (Glut-2) & non-insulin-dependent diabetes (?) \\
\hline PKLR (Pyruvate kinase, liver and RBC type) & 2 & $\begin{array}{l}\text { 1q21 } \\
\text { Satoh et al. (1988) }\end{array}$ & 3(Pklr) & pyruvate kinase deficiency hemolytic anemia \\
\hline TP53 (Tumor protein p53) & 5 & $\begin{array}{l}17 \mathrm{p} 13.1 \\
\text { Isobe et al. (1986) }\end{array}$ & 11(Trp53) & colorectal cancer; Li-Fraumeni syndrome \\
\hline
\end{tabular}

aAll references for the mouse loci from Silver, L.M. (1993)
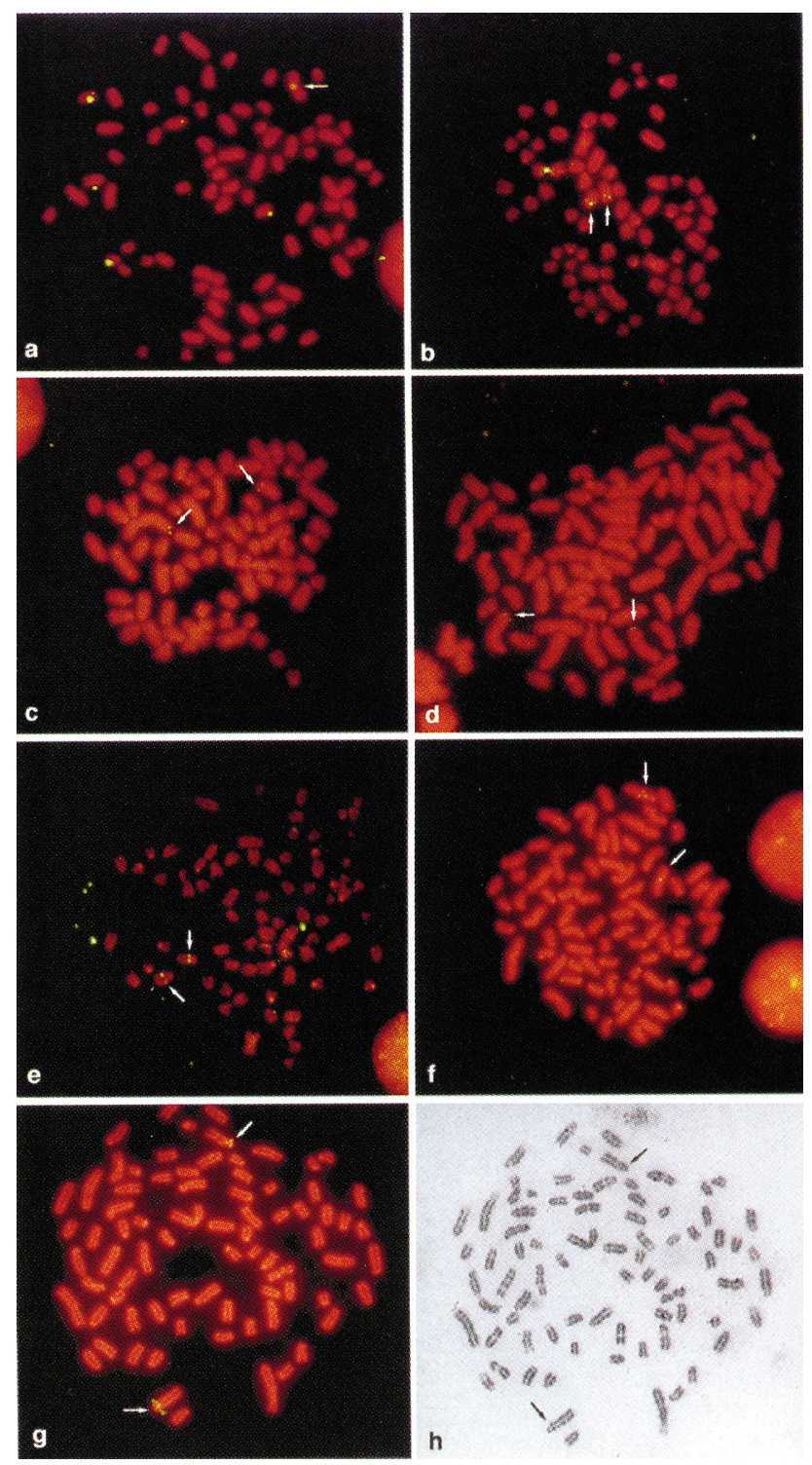

Fig. 1. Metaphases showing distinct fluorescence signals (arrows) on dog chromosomes after hybridization with the following cosmid probes: (a) Menkes on Xq; (b) APRT on Chr 3; (c) CKMM on Chr 4; (d) TP53 on Chr 5; (e) GLUT2 on Chr 5; (f) CSF1R on Chr 5; (g) PKLR on Chr 2; (h) shows the same metaphase as in (g), stained after FISH to identify chromosomes by G-banding. autosomal genes, at least $50 \%$ of chromatids showed signal in all cases.

Figure 1 shows examples of signals obtained from each locus, and an example of a G-banded metaphase stained after carrying out the FISH procedure.

\section{Discussion}

These six autosomal genes localized to canine chromosomes are the first autosomal genes to be physically mapped in the dog. We have great confidence in the assignments, based on the idiogram by Stone and associates (1991). There is some discussion of developing an internationally agreed upon karyotype for the dog. We have employed the one developed by Stone and colleagues (1991) since it is the most recent and the best described. In any case, the canine chromosomal assignments of the genes in Table 1 can be easily reassigned if a different idiogram is eventually agreed upon. Another idiogram for the canine chromosomes has been proposed by Selden and coworkers (1975). In the case of the loci studied in this paper, it is possible to assign chromosome numbers based on Selden's idiogram as well: Chr 4 is the same in both idiograms, and $\mathrm{Chr} 2,3$, and 5 would be 6,5 , and 7 respectively.

It is interesting that three of the six genes are assigned to canine Chr 5. This appears to be simply due to chance. Two of these genes (GLUT2 and CSF1R) are relatively close together, while the third (TP53) is distant from the other two. None of these loci are syntenic in the mouse or the human. Inspection of the current human and mouse genome maps indicates that GLUT2 is not located in a conserved linkage group but that CSF1R and TP53 are in relatively well conserved regions between mouse Chr 18 and human Chr 5q and between mouse Chr 11 and human Chr 17p respectively (Mouse Genome Database 1995).

The canine genome map is in its infancy. Our long-range goal is to put over 600 markers on the canine map. We have developed 500 microsatellite markers and 125 anchor loci markers. Anchor loci are small pieces of actual canine genes, highly conserved in other species, generally the mouse and human (Venta et al., manuscript submitted). It is the cosmids containing six of these anchor loci that we have mapped in this study. Thus, using the anchor loci already developed, we have the potential to map approximately 125 canine genes with the FISH technique.

For mapping the microsatellites, we plan to use a linkage approach, much as with the Centre d'Etudes du Polymorphisme Humain $(\mathrm{CEPH})$ human families. This linkage study will include the anchor loci, which will allow the mapping of the microsatellites on chromosomes relative to the anchor loci.

There is considerable conservation of linkage homology across mammalian species. The mapping of the anchor loci will allow 
investigators studying dog genetic diseases to begin developing a better list of candidate genes for specific genetic diseases, based on potential homologs in other species.

Acknowledgments. We wish to thank K. McFarlin for help with the techniques, J. Beals for producing the figure, and N. Moorman for typing the manuscript. This study was supported by grants from the Morris Animal Foundation, the Orthopedic Foundation for Animals, and the American Kennel Club.

\section{References}

Fratini, A., Simmers, R.N., Callen, D.F., Hyland, V.J., Tischfield, J.A., Stambrook, P.J., Sutherland, G.R. (1986). A new location for the human adenine phosphoribosyltransferase gene (APRT) distal to the haptoglobin (HP) and fra (16) (q23) (FRA16D) loci. Cytogenet. Cell Genet. 43, $10-13$.

Fukumoto, H., Seino, S., Imura, H., Seino, Y., Eddy, R.L., Fukushima, Y., Byers, M.G., Shows, T.B., Bell, G.I. (1988). Sequence, tissue distribution, and chromosomal localization of mRNA encoding a human glucose transporter-like protein. Proc. Natl. Acad. Sci. USA 85, 5434-5438.

Isobe, M., Emanuel, B.S. Givol, D., Oren, M., Croce, C.M. (1986). Localization of gene for human p53 tumour antigen to band $17 \mathrm{p} 13$. Nature 320, 84-85.

Le Beau, M.M., Westbrook, C.A., Diaz, M.O., Larson, R.A., Rowley, J.D., Gasson, J.C., Golde, D.W., Scherr, C.J. (1986). Evidence for the involvement of GM-CSF and FMS in the deletion (5q) in myeloid disorders. Science 231, 984-987.
Mouse Genome Database (MGD) (July, 1995), Mouse Genome Informatics Project, The Jackson Laboratory, Bar Harbor, Maine. World Wide Web (URL: http://www.informatics.jax.org).

Nigro, J.M., Schweinfest, C.W., Rajkovic, A., Pavlovic, J., Jamal, S., Dottin, R.P., Hart, J.T., Kamarck, M.E., Rae, P.M.M., Carty, M.D., MartinDeLeon, P. (1987). cDNA cloning and mapping of the human creatine kinase M gene to $19 q 13$. Am. J. Hum. Genet. 40, 115-125.

Sambrook, J., Fristch, E.F., Maniatis, T. (1989). Molecular Cloning: A Laboratory Manual, 2nd ed. (Cold Spring Harbor, N.Y.: Cold Spring Harbor Laboratory Press).

Satoh, H., Tani, K., Yoshida, M.C., Sasaki, M., Miwa, S., Fuji, H. (1988). The human liver-type pyruvate kinase (PKL) gene is on chromosome 1 at band q21. Cytogenet. Cell Genet. 47,132-133.

Selden, J.R., Moorhead, P.S., Oehlert, M.L., Patterson, D.F. (1975). The Giemsa banding pattern of the canine karyotype. Cytogenet. Cell Genet. $15,380-387$.

Silver, L.M. (1993). Master locus list (Encyclopedia of the Mouse Genome III) Mamm. Genome 4 (Suppl.), S2-S9.

Stone, D.M., Jacky, P.B., Prieur, D.J. (1991). The giemsa banding pattern of canine chromosomes, using a cell synchronization technique. Genome 34, 407-412.

Verga, V., Hall, B.K., Wang, S., Johnson, S., Higgins, J.V., Glover, T.W. (1991). Localization of the translocation breakpoint in a female with Menkes syndrome to Xq13.2-q13.3 proximal to PGK-1. Am. J. Hum. Genet. 48, 1133-1138.

Yu, J., Tong, S., Yang-Feng, T., Kao, F-T. (1992). Construction and characterization of a region-specific microdissection library from human chromosome 2q35-q37. Genomics 14, 769-774. 